\title{
Randomized Study of Aprotinin and DDAVP to Reduce Postoperative Bleeding After Cardiopulmonary Bypass Surgery
}

\author{
Eduardo Rocha, MD; Francisco Hidalgo, MD; Rafael Llorens, MD; José M. Melero, MD; \\ José L. Arroyo, MD; José A. Páramo, MD
}

\begin{abstract}
Background Patients on cardiopulmonary bypass (CPB) have an increased susceptibility to postoperative bleeding. Previous reports using desmopressin acetate (DDAVP) for the prevention of postoperative bleeding have given contradictory results, whereas the protease inhibitor aprotinin has been shown to reduce blood loss after this type of surgery. This randomized study was performed to assess the efficacy of DDAVP versus aprotinin in the prevention of bleeding after CPB.

Methods and Results One hundred nine of 122 eligible patients were randomized to four different groups: Group A $(n=28)$ received aprotinin starting with a bolus of $2 \times 10^{6} \mathrm{KIU}$ followed by a continuous infusion of $0.5 \times 10^{6} \mathrm{KIU} / \mathrm{h}$ until the end of surgery; group B $(n=25)$ received of DDAVP $0.3 \mu \mathrm{g} / \mathrm{kg}$ IV on completion of $\mathrm{CPB}$; group $\mathrm{C}(\mathrm{n}=28)$ received two doses of DDAVP, the first as in group $B$ and an additional dose 6 hours after surgery; group $D(n=28)$ received no treatment. There was a marked reduction of postoperative blood loss either at 12 hours $(P<.01)$ or 72 hours $(P<.02)$ in the aprotinin
\end{abstract}

group compared with all other groups, whereas no significant effect was observed in either of the two DDAVP regimens. A significant reduction in the amount of blood used was observed only in the aprotinin group $(P<.01)$. Of the plasma fibrinolytic components assayed, there was a significant reduction of the fibrin degradation product generation in the aprotinin group $(P<.001)$, whereas a significant systemic hyperfibrinolysis was observed in both DDAVP-treated groups and the control group. No side effects related to the study drugs were observed in any patient.

Conclusions Aprotinin inhibited fibrinolysis; this correlated with a significant reduction of postoperative blood loss and need for blood replacement after CPB. Neither one nor two doses of DDAVP had a beneficial effect. Aprotinin offers a better alternative than DDAVP in the prevention of bleeding after CPB. (Circulation. 1994;90:921-927.)

Key Words • cardiopulmonary bypass • desmopressin acetate $\bullet$ aprotinin $\bullet$ fibrinolysis
$\mathrm{D}$ espite the improvement in surgical techniques and extracorporeal circulation, excessive perioperative bleeding continues to complicate cardiopulmonary bypass (CPB) surgery. Patients undergoing CPB often require blood component therapy, reoperation for bleeding control is sometimes necessary, and occasionally life-threatening hemorrhage occurs during the postoperative period..$^{1,2}$

The majority of patients bleed primarily from the operative site, and the excessive bleeding is related to the surgical damage to blood vessels. In some patients, however, diffuse systemic bleeding suggests an acute acquired hemostatic defect. The basic pathophysiology of altered hemostasis associated with CPB remains confusing because of the complexity of the hemostatic process and the many uncontrolled variables associated with CPB, such as the surgical procedure, type of anesthesia, drug administration, transfused blood products, hypothermia, hemodilution, and the type of oxygenator. The abnormalities most frequently found include heparin and protamin excess, heparin rebound,

Received January 26, 1994; revision accepted May 6, 1994

From the Hematology (E.R., J.A.P.), Anesthesiology (F.H., J.L.A.), and Cardiovascular Surgery (R.L., J.M.M.) Departments, Clinica Universitaria, School of Medicine, University of Navarra, Pamplona, Spain.

Correspondence to E. Rocha, Hematology Service, Clinica Universitaria, PO Box 192, 31080 Pamplona, Spain.

(C) 1994 American Heart Association, Inc. low platelet count, low fibrinogen and other coagulation factors, primary fibrinolysis, and disseminated intravascular coagulation..$^{3-7}$ However, the major contributor to abnormal hemostasis seems to be the alteration of platelet function resulting from a reversible membrane abnormality. ${ }^{8,9}$

Research during the past decade has been addressed at reducing postoperative blood loss and transfusion requirements in routine CPB operations. Among the different treatment schedules used, desmopressin acetate (DDAVP) and fibrinolysis inhibitors seem to be the most efficacious in diminishing blood loss after cardiac surgery.

DDAVP is a synthetic analogue of the neurohypophyseal nonapeptide arginine vasopressin. It is known that this hormone causes the appearance of larger von Willebrand factor (vWF) multimers in addition to increased concentrations of vWF and factor VIII; thus, a role for DDAVP has been indicated in patients with mild hemophilia or von Willebrand's disease. ${ }^{10}$ DDAVP has also been shown to shorten the bleeding time in other conditions, including uremia, chronic liver disease, and aspirin ingestion. ${ }^{11-13}$ Finally, although DDAVP has been shown to be effective in reducing bleeding after orthopedic ${ }^{14}$ and cardiac surgery, ${ }^{15}$ the beneficial effect in CPB remains unclear. ${ }^{16,17}$

Aprotinin is a serine protease inhibitor with inhibitory effects on human plasmin, trypsin, and kallikrein that has been shown to reduce postoperative blood loss 
and the need for blood transfusion in cardiac surgery through an inhibition of fibrinolysis mechanisms. ${ }^{18,19}$ As already mentioned, alterations in platelet surface membrane receptors have been described during extracorporeal circulation, ${ }^{9,20}$ and it appears that aprotinin also preserves platelet function. ${ }^{19}$

Previous studies have reported some adverse effects attributable to the use of both DDAVP and aprotinin, especially in patients undergoing revascularization procedures, since they may increase the risk of graft thrombosis. ${ }^{21,22}$

We therefore undertook a randomized clinical study to compare the effectiveness of aprotinin versus DDAVP in reducing postoperative blood loss in patients undergoing cardiac surgery with extracorporeal circulation.

\section{Study Population}

\section{Methods}

To be eligible for recruitment, patients had to satisfy the following inclusion criteria: age $>18$ years and valvular or coronary disease. Patients were excluded for the following reasons: emergency surgery, known hemostatic defect, hepatic and renal insufficiency, previous exposure to the study drugs, and use of other techniques of blood saving. Patients receiving nonsteroidal anti-inflammatory drugs or aspirin before surgery were not excluded, because a large percentage of patients undergoing routine $\mathrm{CPB}$ at our institution are on these medications up to the time of surgery.

Heparin was administered at an initial dose of $300 \mathrm{U} / \mathrm{kg}$ to maintain the activated clotting time $>400$ seconds (Hemochrom Internationaltechnique). CPB was instituted with a two-stage right atrial and ascending aortic cannula. A roller pump maintained nonpulsatile flow between 2.0 and 2.4 $\mathrm{L} \cdot \mathrm{min}^{-1} \cdot \mathrm{m}^{-2}$. Moderate systemic hypothermia $\left(25^{\circ} \mathrm{C}\right)$ was maintained during aortic occlusion. After discontinuation of $\mathrm{CPB}$, heparin was reversed with protamine sulfate $(1.5: 1)$ by slow intravenous infusion.

\section{Study Design}

The protocol was approved by our hospital's Clinical Assays Committee. After informed consent was obtained, a prospective randomized trial involving 122 patients was begun. Of the total number of patients admitted to the study, 13 (4 in the placebo group and 9 in the treatment groups) were excluded from subsequent analysis because they did not complete the study. The remaining 109 patients were assigned to one of the following groups.

Group A patients $(n=28)$ received aprotinin (Trasylol) supplied by Bayer in bottles containing $70 \mathrm{mg}$ aprotinin (500 000 kallikrein inactivator units, KIU) in $50 \mathrm{~mL} 0.9 \%$ saline solution without further additives or preservative substances. Patients in this group received a bolus infusion of $2 \times 10^{6} \mathrm{KIU}$ within 30 minutes after induction of anesthesia followed by a continuous infusion of $0.5 \times 10^{6} \mathrm{KIU} / \mathrm{h}$ until the patient left the operating room and an additional bolus of $2 \times 10^{6} \mathrm{KIU}$ aprotinin in the pump prime by replacement of crystalloid solution.

Group B patients $(n=25)$ received DDAVP, $0.3 \mu \mathrm{g} / \mathrm{kg}$ body wt (supplied by Ferring Pharmaceuticals) in a $50-\mathrm{mL}$ saline solution over a period of 20 minutes, given intravenously on completion of CPB and immediately after administration of protamine.

Group C patients $(n=28)$ received two doses of DDAVP, $0.3 \mu \mathrm{g} / \mathrm{mL}$, the first as in group B and an additional dose 6 hours after surgery.

Group D patients $(n=28)$ did not receive aprotinin or DDAVP and were considered a control group.

\section{Blood Sampling}

Blood samples were obtained before operation, at the end of bypass, and 90 minutes and 24 hours after surgery. Venous blood was drawn in Vacutainer tubes (Becton Dickinson) containing $0.129 \mathrm{~mol} / \mathrm{L}$ sodium citrate in a 9:1 proportion. Platelet-poor plasma was prepared by centrifugation at $1500 \mathrm{~g}$ for 20 minutes and snap-frozen in aliquots at $-70^{\circ} \mathrm{C}$ until used. For measurements of hemoglobin and hematocrit, blood was mixed with EDTA.

\section{Procedures}

Hematocrit and hemoglobin were determined by routine analysis with a Coulter S Plus II. Plasminogen and $\alpha_{2}$-antiplasmin were determined by amidolytic assays (Coatest Plasminogen and Coatest Antiplasmin, Kabi Diagnostica). Plasminogen activator inhibitor type 1 (PAI-1) activity was measured with chromogenic substrates as previously described. ${ }^{23}$ Tissue-type plasminogen activator (TPA) antigen was measured with a commercially available ELISA assay (TintElize t-PA, Biopool). Fibrin degradation products (FbDP) were assayed by use of a specific monoclonal antibody as described by Nieuwenhuizen ${ }^{24}$ (Fibrinostika FbDP, Organon Teknika). Data presented in the figures and used in the statistical calculations are values measured on plasma samples corrected for hemodilution, as assessed by the difference between each hematocrit with respect to its own baseline value.

The postoperative blood loss in the first 72 hours was determined by measuring the drainage losses. Red cell transfusions within the first 72 hours were also measured. Blood pressure and urine output in the first 24 hours were recorded.

Investigators and laboratory personnel were blinded to treatment or control groups.

\section{Statistical Analysis}

Results are expressed as mean \pm SD. Student's $t$ test was used to compare mean values, and Student's $t$ test for paired observations was used to compare the mean values of the same variable at different times. Statistical analysis for group comparisons was performed with a two-way ANOVA. Differences were considered to be significant when $P<.05$.

\section{Results}

One hundred twenty-two patients who consented to participate in this trial were randomized into four different groups, and 109 completed the study. The baseline characteristics, the main diagnoses, and types of surgery are listed in Table 1 . There were no significant differences with regard to any of the characteristics analyzed among the four group of patients. Only one patient in the control group had a previous intrathoracic operation, compared with the greater number of patients in the treated groups. However, no significant differences could be demonstrated.

All patients had normal coagulation parameters, platelet counts, and hemoglobin levels before surgery.

\section{Blood Loss and Transfusion Requirements}

As shown in Table 2 and Fig 1, there was a marked reduction $(P<.01)$ of postoperative blood loss during the first 12 hours in the group treated with aprotinin $\left(137.9 \pm 70.6 \mathrm{~mL} / \mathrm{m}^{2}\right)$ compared with groups B $(278.7 \pm$ $\left.164.1 \mathrm{~mL} / \mathrm{m}^{2}\right), C\left(208.8 \pm 111.7 \mathrm{~mL} / \mathrm{m}^{2}\right)$, and $\mathrm{D}(214.5 \pm$ $120.8 \mathrm{~mL} / \mathrm{m}^{2}$ ), with no differences between groups $B$ and $C$ and the control group. The total postoperative blood loss at 72 hours was also reduced $(P<.02)$ in the aprotinin group $\left(358.5 \pm 156.3 \mathrm{~mL} / \mathrm{m}^{2}\right)$ compared with groups $B$ $\left(551.8 \pm 324.1 \mathrm{~mL} / \mathrm{m}^{2}\right), C\left(498.5 \pm 235.6 \mathrm{~mL} / \mathrm{m}^{2}\right)$, and $\mathrm{D}$ $\left(438.7 \pm 228.1 \mathrm{~mL} / \mathrm{m}^{2}\right)$. 
TABle 1. Characteristics of the Patients Studied

\begin{tabular}{lcccc}
\hline & $\begin{array}{c}\text { Group A } \\
(\mathbf{n}=28)\end{array}$ & $\begin{array}{c}\text { Group B } \\
(\mathbf{n}=25)\end{array}$ & $\begin{array}{c}\text { Group C } \\
(\mathbf{n}=28)\end{array}$ & $\begin{array}{c}\text { Group D } \\
(\mathbf{n}=28)\end{array}$ \\
\hline Age, $y$ & $58.9 \pm 10.0$ & $56.6 \pm 8.8$ & $57.3 \pm 76$ & $56.3 \pm 10.1$ \\
Sex, M/F & $16 / 12$ & $14 / 11$ & $20 / 8$ & $22 / 6$ \\
Body surface, $\mathrm{m}^{2}$ & $1.7 \pm 0.2$ & $1.7 \pm 0.1$ & $1.8 \pm 0.2$ & $1.8 \pm 0.1$ \\
Type of surgery & & & 16 & 14 \\
$\quad$ Coronary & 13 & 12 & 11 & 14 \\
$\quad$ Valvular & 14 & 12 & 1 & 0 \\
$\quad$ Mixed & 1 & 1 & 6 & 1 \\
Reintervention & 4 & 4 & $131.6 \pm 39.3$ & $121.3 \pm 36.2$ \\
Duration of extracorporeal circulation, $\min$ & $127.3 \pm 45.4$ & $122.4 \pm 34.4$ & & \\
\hline
\end{tabular}

Values are mean \pm SD.

There was also a significant reduction in the amounts of bank blood used in the aprotinin group, either in the first 12 hours $(P<.02)$ or at 72 hours after surgery $(P<.01)$ (Table 2). The total blood transfused was $366.1 \pm 331.9$ $\mathrm{mL} / \mathrm{m}^{2}$ in group $\mathrm{A}$, which was significantly less than in groups $B\left(740.4 \pm 416.3 \mathrm{~mL} / \mathrm{m}^{2}\right), C\left(662.8 \pm 380.7 \mathrm{~mL} / \mathrm{m}^{2}\right)$, and $\mathrm{D}\left(678.1 \pm 462.2 \mathrm{~mL} / \mathrm{m}^{2}\right)$, without differences in the two DDAVP-treated groups compared with the control group.

\section{Hemoglobin Levels}

The preoperative hemoglobin levels were similar in all groups. At 24 hours after surgery, the levels in all groups fell a similar amount (Fig 2).

\section{Fibrinolytic System}

Table 3 shows the preoperative, intraoperative, and postoperative evolution of the different fibrinolysis parameters analyzed in the control group. In patients who did not receive any treatment, we observed a significant decrease of plasminogen and $\alpha_{2}$-antiplasmin $(P<.001)$ and a marked increase of TPA antigen, PAI-1, and FbDP $(P<.001)$ intraoperatively compared with the baseline value. Whereas plasminogen and $\alpha_{2}$-antiplasmin showed a tendency to recover in the sample taken 90 minutes after operation with normalization on postoperative day 1, the TPA, PAI-1, and FbDP concentrations remained significantly elevated after surgery $(P<.01)$.

There were no significant differences among the three treatment groups with regard to plasminogen and PAI-1 concentrations in relation to values observed in the control group (data not shown). TPA antigen (Fig 2) was slightly elevated in both DDAVP-treated groups only in the sample taken 90 minutes after surgery, with differences in relation to the corresponding levels in groups $\mathrm{A}$ or $\mathrm{D}(P<.05)$. Whereas the intraoperative and postoperative levels of $\alpha_{2}$-antiplasmin did not change significantly in the aprotinin group with respect to the preoperative value, a reduction similar to that in the control group was observed in both DDAVP-treated groups. $\alpha_{2}$-Antiplasmin levels recovered in all groups in the sample taken 24 hours after surgery (Fig 2). A significant reduction of FbDP generation could be demonstrated in patients receiving aprotinin in the samples obtained at the end of bypass and immediately after surgery $(P<.001)$, but no differences in this parameter were observed in both DDAVP-treated groups in relation to the control group (Fig 2).

No correlations between the different fibrinolysis parameters analyzed and either the blood loss or transfusion requirements could be demonstrated.

\section{Side Effects}

Neither DDAVP nor aprotinin provoked complications with regard to blood pressure or urinary output. No thrombosis, deaths, or severe complications occurred intraoperatively or during the first 10 postoperative days in any patients included in the study.

\section{Discussion}

The use of CPB for cardiac surgery is performed routinely in western countries and is generally regarded as safe, although these patients are at considerable risk of postoperative bleeding requiring blood transfusion and reoperation in approximately $3 \%$ of cases. It is well known that cardiac surgery with CPB results in large alterations in hemostasis and platelet function, so there

TABLe 2. Results of the Study

\begin{tabular}{lcccr}
\hline & Group A & Group B & Group C & Group D \\
\hline Blood loss, $\mathrm{mL} / \mathrm{m}^{2}$ & & & & \\
$\quad 0-12 \mathrm{~h}$ & $137.9 \pm 70.6^{\star}$ & $278.7 \pm 164.1$ & $208.8 \pm 111.7$ & $214.5 \pm 120.8$ \\
$\quad$ Total, 0-72 h & $358.5 \pm 156.3 \dagger$ & $551.8 \pm 324.1$ & $498.5 \pm 235.6$ & $438.7 \pm 228.1$ \\
Red cell transfusions, $\mathrm{mL} / \mathrm{m}^{2}$ & & & & \\
0-12 $\mathrm{h}$ & $164.5 \pm 197.5 \dagger$ & $366.9 \pm 233.6$ & $238.1 \pm 258.6$ & $340.9 \pm 324.3$ \\
Total, 0-72 h & $366.1 \pm 331.9^{\star}$ & $740.4 \pm 416.3$ & $662.8 \pm 380.7$ & $678.1 \pm 462.2$ \\
\hline
\end{tabular}

${ }^{\star} P<.01$ and $+P<.02$ aprotinin in relation to all other groups. 

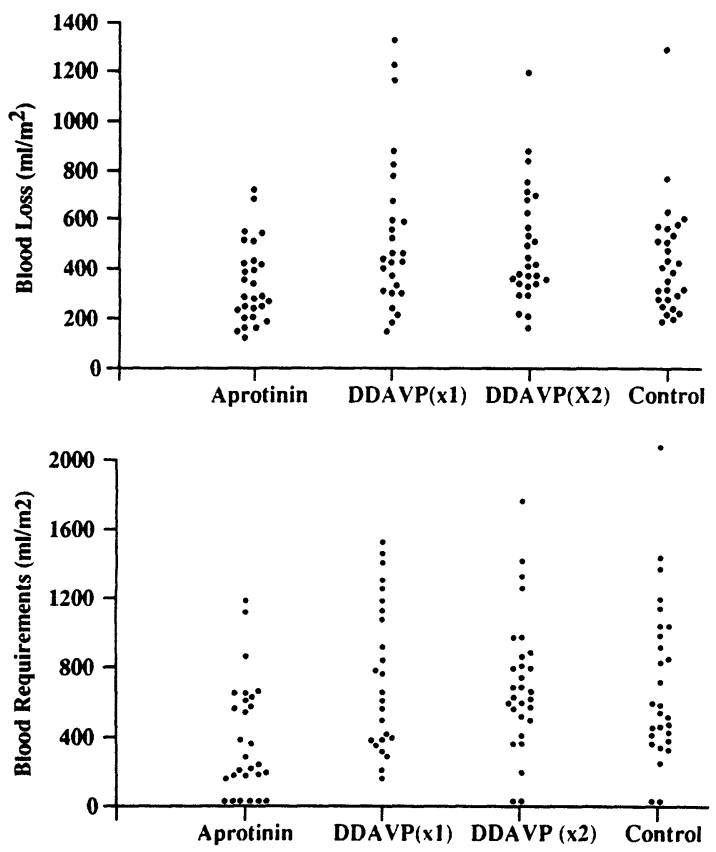

FIG 1. Scatterplots showing individual distribution of blood loss (top) and red cell transfusions (bottom) in the treated groups and in the control group. DDAVP indicates desmopressin acetate.

has been great interest in improving postoperative hemostasis by use of drugs that prevent alterations in those systems. ${ }^{2}$

This randomized study convincingly shows that aprotinin is a useful drug in reducing postoperative blood loss as well as the need for blood transfusion in patients undergoing CPB surgery, whereas neither one nor two doses of DDAVP were able to significantly reduce either blood loss or transfusion requirements.

The hemostatic properties of DDAVP in patients undergoing open-heart surgery with CPB were first studied by Czer et $\mathrm{al}^{25}$ in a prospective nonrandomized clinical study. Patients treated with DDAVP required significantly less transfusion of blood products. Moreover, DDAVP infusion shortened the bleeding time and significantly increased factor VIII and vWF levels. Salzman et $\mathrm{al}^{15}$ performed a double-blind prospective trial in which patients were randomized to DDAVP or placebo. The DDAVP-treated patients showed a significant reduction in intraoperative and postoperative blood loss and lower red cell transfusion requirements. In these patients, higher vWF:Ag levels than those in the placebo group were observed 90 minutes after infusion. In the light of these results, it seemed that the beneficial effect of DDAVP in CPB was probably related to an elevation of vWF in plasma. In another study, however, the effectiveness of DDAVP in reducing blood loss could not be related to the increase of large vWF multimers. ${ }^{26}$

In a randomized trial comparing DDAVP versus placebo, we could not confirm that DDAVP reduces the total blood loss and transfusion requirements, although it was observed to significantly reduce intraoperative blood loss. ${ }^{16}$ These results were later confirmed by Hackmann et al..$^{27}$ Furthermore, four additional studies did not find significant improvement in postoperative blood loss, ${ }^{28-31}$ and one report shows that the total postoperative blood loss and the red cell transfusion rates were significantly higher in the DDAVP group than in the control group, which could be related to the DDAVP-induced TPA release from endothelial cells and subsequent fibrinolysis. ${ }^{32}$

Since, as suggested by our findings, the administration of DDAVP was effective only in reducing intraoperative bleeding, we decided to administer a second dose 6 hours after surgery to establish whether it could also improve the postoperative blood loss. The results of the present study clearly indicate that a second dose of DDAVP given after surgery does not reduce postoperative bleeding. It could be speculated that a tachyphylaxis phenomenon could hamper the possible benefit of DDAVP, but it is unlikely that later administration could be more effective. ${ }^{33}$ There is evidence that the administration of DDAVP may be useful in reducing hemorrhage in patients at high risk, such as those undergoing valve replacement combined with coronary artery bypass graft surgery or in those with aspirinrelated bleeding after bypass, or even in patients with severe platelet dysfunction and excessive mediastinal bleeding after termination of CPB. ${ }^{34,35}$ However, the majority of patients who undergo cardiac surgery without complications will have only moderate blood loss, and in these cases DDAVP does not appear to offer any advantages beyond those of conventional techniques to reduce the use of blood products. Thus, DDAVP could be administered to patients who are at particular risk of bleeding but not routinely to all patients undergoing CPB surgery. ${ }^{17,36}$

Aprotinin has been used in patients having cardiac surgery since the 1960s on the basis of a reduction of the hyperfibrinolytic state observed during open-heart operations. 37,38 These reports indicated that relatively low doses of aprotinin significantly reduced fibrinolytic activity but had no effect on postoperative bleeding. More recent data suggested that high-dose aprotinin might reduce bleeding after cardiac surgery not only by inhibiting fibrinolysis but also by preserving platelet function. ${ }^{18,19,39-42}$ These results have clearly been confirmed in the present study, in which a high-dose aprotinin regimen significantly diminished the blood loss and transfusion requirements compared with either the control group or the two DDAVP-treated groups.

Although it has been suggested that both DDAVP and antifibrinolytic drugs may cause premature saphenous vein graft occlusion, several prospective studies reported no increase in the frequency of occlusion..$^{27,39,43}$ Two recent reviews evaluating the incidence of thrombotic events in controlled trials of DDAVP in cardiac surgery also indicate that DDAVP does not increase the incidence of thrombosis. ${ }^{44,45}$ In our study, there were no incidences of suspected acute graft thrombosis in either of the treated groups, although no patients in either group underwent angiography to demonstrate patent bypass grafts. Very recently, however, Cosgrove et $\mathrm{al}^{46}$ reported a significant incidence of graft thrombi in postmortem examinations of patients receiving aprotinin who died during the study. The evidence of vein graft thrombosis raises the question of a hypercoagulable state that may adversely influence patient outcome. Other complications with the use of aprotinin include allergic reactions, renal toxicity, and heparin resistance. ${ }^{47}$ We observed no significant allergic complica- 

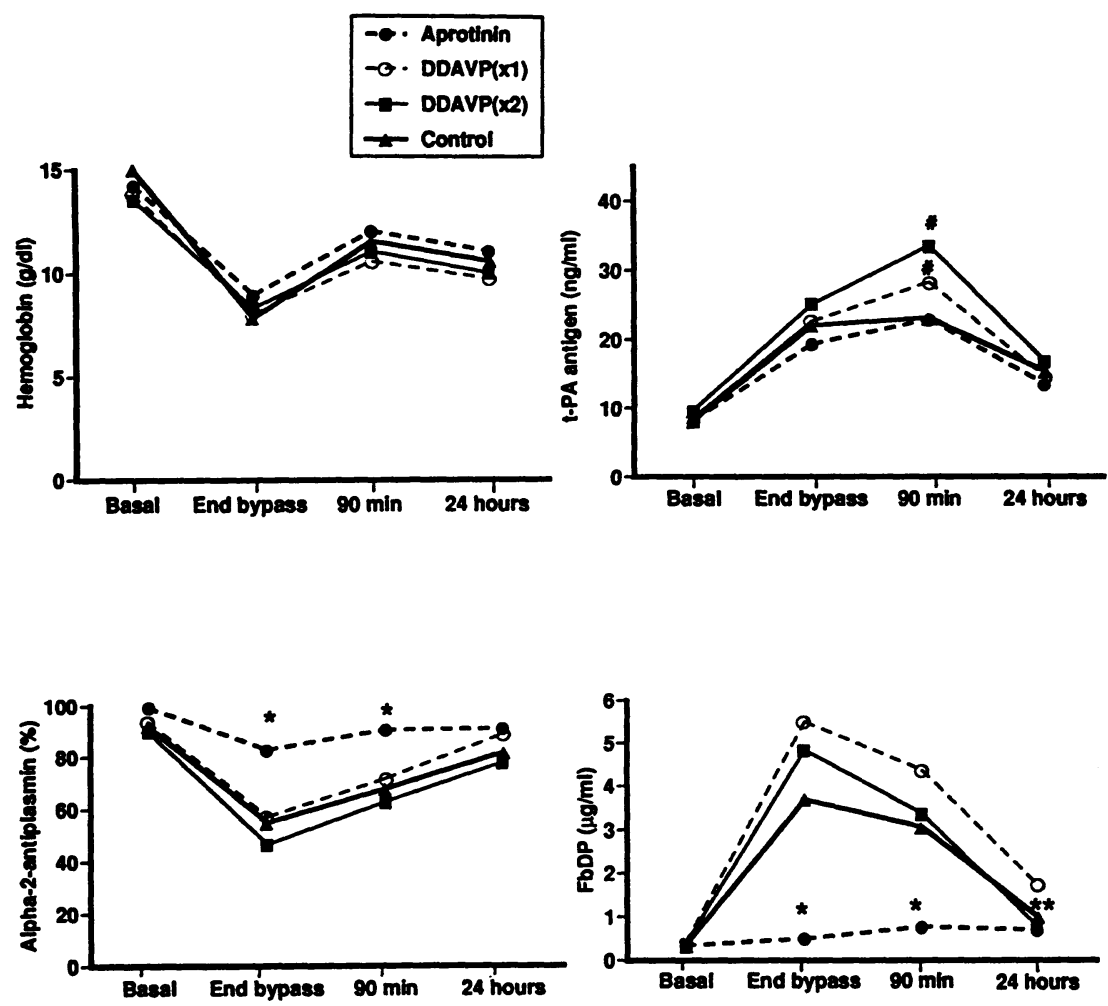

FIG 2. Graphs showing mean hemoglobin, tissue-type plasminogen activator (tPA), $\alpha_{2}$-antiplasmin, and fibrin degradation product (FbDP) concentration in blood samples obtained before operation, at the end of bypass, and 90 minutes and 24 hours after surgery in aprotinin, one dose of desmopressin acetate (DDAVP), two doses of DDAVP, and control groups. $\star P<.001$ aprotinin compared with all other groups; ${ }^{*} P<.05$ aprotinin compared with one dose DDAVP; \#P<.05 both DDAVP. treated groups compared with aprotinin and control groups. tions or drug interactions in our study. In an attempt to document whether the beneficial effect of aprotinin in reducing bleeding would be related to an inhibition of fibrinolysis, we compared the changes observed in different fibrinolysis parameters measured preoperatively, intraoperatively, and postoperatively in the placebo group and in the treated groups. Hyperfibrinolysis during and after CPB is well documented in the literature ${ }^{48-50}$ and was also found in the present study, as demonstrated by a significant decrease of plasminogen and $\alpha_{2}$-antiplasmin and an increase of TPA and FbDP observed in the control group. Whether this hyperfibrinolytic state is a primary event or secondary to the activation of the coagulation system is not completely understood, 51 but the clinical significance of hyperfibrinolysis for the amount of postoperative blood loss is well shown by laboratory data and the results of therapeutic intervention studies.

Neither of the two DDAVP regimens significantly improved the intraoperative and postoperative fibrinolysis alterations observed in the control group, but they induced a slight increase of TPA concentrations. It has been shown that DDAVP induces a rapid release of TPA from its endothelial cell storage sites with a subsequent fall in PAI-1 activity, which was thought to be due to the formation of TPA/inhibitor complexes. ${ }^{52}$ The lack of differences in the DDAVP-treated patients compared with the control group might be due to the transient effect of the drug reaching a peak 20 minutes after intravenous delivery and thus not detected in the sample obtained at the end of bypass. Aprotinin inhibited excessive fibrinolysis by preventing the plasminogen and $\alpha_{2}$-antiplasmin consumption and FbDP generation. Whereas the observed changes in $\alpha_{2}$-antiplasmin might be an artifact in relation to the chromogenic assay, it seems clear that aprotinin treatment resulted in a reduction of intraoperative and postoperative hyperfibrinolysis as assessed by the decrease of FbDP levels.

Other studies have used a similar schedule to maintain a constant intraoperative plasma aprotinin concentration of approximately $4 \mu \mathrm{mol} / \mathrm{L}$. This concentration has been reported to inhibit plasmin in vitro, to prevent platelet activation and aggregation, and to block the loss of platelet membrane glycoprotein Ib during CPB.41,42,53,54 It has

TABLE 3. Values of Fibrinolysis Parameters Studied in the Control Group

\begin{tabular}{lcccc}
\hline & Preoperatlve & $\begin{array}{c}\text { End of } \\
\text { Bypass }\end{array}$ & $90 \mathrm{~min}$ & $24 \mathrm{~h}$ \\
\hline Plasminogen, \% & $91.7 \pm 15.5$ & $78.2 \pm 20.4^{\star}$ & $82.5 \pm 23.5 \dagger$ & $92.6 \pm 27.8$ \\
$\alpha_{2}$-antiplasmin, \% & $92.2 \pm 12.4$ & $55.1 \pm 21.4^{\star}$ & $67.5 \pm 20.7^{\star}$ & $81.3 \pm 19.3 \dagger$ \\
TPA antigen, $\mathrm{ng} / \mathrm{mL}$ & $7.9 \pm 5.5$ & $22.1 \pm 10.9^{\star}$ & $23.0 \pm 6.7^{\star}$ & $15.4 \pm 9.1 \dagger$ \\
PAl-1, U/mL & $9.6 \pm 8.4$ & $24.3 \pm 21.7 \dagger$ & $34.4 \pm 16.9^{\star}$ & $26.8 \pm 17.3 \dagger$ \\
FbDP, $\mu \mathrm{g} / \mathrm{mL}$ & $0.3 \pm 0.2$ & $3.7 \pm 2.5^{\star}$ & $3.1 \pm 1.9^{\star}$ & $0.9 \pm 0.7 \dagger$ \\
\hline
\end{tabular}

TPA indicates tissue-type plasminogen activator; PAl-1, plasminogen activator inhibitor; and FbDP, fibrin degradation products. Values are mean $\pm S D$. ${ }^{*} P<.001$ and $+P<.01$ with respect to the preoperative value. 
been hypothesized that aprotinin reduces blood loss after CPB by stabilizing the platelet membrane by means of its antifibrinolytic effects. However, it is not clear whether these effects of aprotinin on normalizing hemostatic function might be exclusively related to inhibition of plasmin or inhibition of other coagulation cascade serine proteases. ${ }^{55}$

Other lysine-analogue antifibrinolytic preparations such as $\epsilon$-aminocaproic acid and tranexamic acid also appear safe in decreasing blood loss and transfusion requirements after cardiac surgery. ${ }^{56,57}$ Interestingly, Horrow et al ${ }^{58}$ investigated the separate and combined hemostatic effects of tranexamic acid and DDAVP during cardiac surgery. DDAVP exerted no hemostatic effect with or without prior administration of antifibrinolytic drug.

In summary, aprotinin inhibited fibrinolysis, and that correlated with a significant reduction of postoperative blood loss and need for blood replacement after CPB. Although DDAVP may be effective in reducing hemorrhage in patients at high risk, our results clearly indicate that in the majority of patients, the protease inhibitor aprotinin offers a better alternative than DDAVP in the prevention of bleeding after cardiopulmonary bypass surgery.

\section{References}

1. Bachman F, McKenna R, Cole ER, Najafi H. The hemostatic mechanism after open-heart surgery, I: studies on plasma coagulation factors and fibrinolysis in 512 patients after extracorporeal circulation. J Thorac Cardiovasc Surg. 1975;70:76-85.

2. Woodman RC, Harker LA. Bleeding complications associated with cardiopulmonary bypass. Blood. 1990;76:1680-1697.

3. Bick RL. Hemostasis defects associated with cardiac surgery, prosthetic devices, and other extracorporeal circuits. Semin Thromb Hemost. 1985;11:249-280.

4. Mammen EF, Koets MH, Washington BC, Wolk LW, Brown JM, Burdick M, Selik NR, Wilson RF. Hemostasis changes during cardiopulmonary bypass surgery. Semin Thromb Hemost. 1985;11: 281-292.

5. Kucuk O, Kwaan HC, Frederickson J, Wade L, Green D. Increased fibrinolytic activity in patients undergoing cardiopulmonary bypass operation. Am J Hematol. 1986;23:223-229.

6. Gram J, Janetzko T, Jespersen J, Bruhm HD. Enhanced fibrinolysis following the neutralization of heparin in open heart surgery increases the risk of postsurgical bleeding. Thromb Haemost. 1990;63:241-245.

7. Harker LA. Bleeding after cardiopulmonary bypass. $N$ Engl J Med. 1986;314:1445-1448.

8. George JN, Pickett EB, Saucerman S, McEver R, Kunicki TJ, Kieffer N, Newman PJ. Platelet surface glycoproteins: studies on resting and activated platelets and platelet membrane microparticles in normal subjects and observations in patients during adult respiratory distress syndrome and cardiac surgery. $J$ Clin Invest. 1986;78:340-348.

9. Kestin AS, Valeri CR, Khuri SF, Loscalzo J, Ellis PA, MacGregor H, Birjiniuk V, Ouimet H, Pasche B, Nelson MJ, Benoit SE, Rodino LJ, Barnard MR, Michelson AD. The platelet function defect of cardiopulmonary bypass. Blood. 1993;82:107-117.

10. Mannucci PM. Desmopressin for treatment of disorders of hemostasis. Prog Hemost Thromb. 1986;8:19-45.

11. Mannucci PM, Remuzzi G, Pusineri F, Lombardi R, Valsecchi C, Mecca G, Zimmerman TS. Deamino-8-D-arginine vasopressin shortens the bleeding time in uremia. N Engl J Med. 1983;308:8-12.

12. Kobrinsky NL, Israels ED, Gerrard JM, Cheang MS, Watson CM, Bishop AJ, Schroeder ML. Shortening of bleeding time by 1-deamino-8-D-arginine vasopressin in various bleeding disorders. Lancet. 1984;1:1145-1148.

13. Mannucci PM, Vicente V, Vianello L, Cattaneo M, Alberca I, Coccato MP, Faioni M, Mari D. Controlled trial of desmopressin (DDAVP) in liver cirrhosis and other conditions associated with prolonged bleeding time. Blood. 1986;67:1148-1153.

14. Kobrinsky NL, Letts RM, Patel LR, Israels ED, Monson R, Schwetz N, Cheang MS. 1-Desamino-8-D arginine vasopressin (desmopressin) decreases operative blood loss in patients having
Harrington rod spinal fusion surgery. Ann Intern Med. 1987;107: 446-450

15. Salzman EW, Weinstein MJ, Weintraub RM, Ware JA, Thurer RL, Robertson L, Donovan A, Gaffney T, Bertele V, Smith JTM, Chute LE. Treatment with desmopressin acetate to reduce blood loss after cardiac surgery: a double-blind randomized trial. $N$ Engl J Med. 1986;314:1402-1406.

16. Rocha E, Llorens R, Páramo JA, Arcas R, Cuesta B, Martín Trenor A. Does desmopressin acetate reduce blood loss after surgery in patients on cardiopulmonary bypass? Circulation. 1988; 77:1319-1323.

17. Rocha E, Páramo JA, Llorens R, Hidalgo F. Desmopressin in cardiac surgery with extracorporeal circulation. In: Mariani G, Mannucci PM, Cattaneo M, eds. Desmopressin in Bleeding Disorders. New York, NY: Plenum Press; 1993:191-202.

18. Van Oeveren W, Jansen NJG, Bidstrup BP, Royston D, Westaby S, Neuhof H, Wildevuur CR. Effects of aprotinin on hemostatic mechanisms during cardiopulmonary bypass. Ann Thorac Surg. 1987;44:640-645.

19. Blauhut B, Gross C, Necek S, Doran JE, Spath P, LundsgaardHansen P. Effects of high-dose aprotinin on blood loss, platelet function, fibrinolysis, complement and renal function after cardiopulmonary bypass. J Thorac Cardiovasc Surg. 1991;101:958-967.

20. Harker LA, Malpass TW, Branson HE, Hessel EA, Slichter SJ. Mechanism of abnormal bleeding in patients undergoing cardiopulmonary bypass: acquired transient platelet dysfunction associated with selective alpha-granule release. Blood. 1980;56:824-834.

21. O'Brian JR, Green PJ, Salmon G, Weir P, Colin Jones D, Arnold M, Chopra S. Desmopressin and myocardial infarction. Lancet. 1989;1:664-665.

22. Bohrer H, Fleischer F, Lang J, Vahl C. Early formation of thrombi on pulmonary artery catheters in cardiac surgical patients receiving high-dose aprotinin. J Cardiothorac Anesth. 1990;4:222-225.

23. Páramo JA, Alfaro MJ, Rocha E. Postoperative changes in the plasmatic levels of tissue-type plasminogen activator and its fastacting inhibitor: relationship to deep vein thrombosis and influence of prophylaxis. Thromb Haemost. 1985;54:713-716.

24. Nieuwenhuizen W. The use of monoclonal antibodies in demonstrating different fibrinogen derivatives. In: Muller-Berghaus G, Scheefers-Borchel U, Selmayr E, Henschen A, eds. Fibrinogen and Its Derivatives. Biochemistry, Physiology and Pathophysiology. Amsterdam, the Netherlands: Excerpta Medica; 1986:245-256.

25. Czer L, Bateman T, Gray R, Raymond M, Chaux A, Mattlof J, Stewart M. Prospective trial of DDAVP in treatment of severe platelet dysfunction and hemorrhage after cardiopulmonary bypass. Circulation. 1985;72(suppl III):III-130. Abstract.

26. Weinstein M, Ware JA, Troll J, Salzman E. Changes in von Willebrand factor during cardiac surgery: effect of desmopressin acetate. Blood. 1988;71:1648-1655.

27. Hackmann T, Gascoyne RN, Naiman SC, Growe GH, Burchill LD, Jamieson E, Sheps S, Schechter MT, Townsend GE. A trial of desmopressin (1-desamino-8-D-arginine vasopressin) to reduce blood loss in uncomplicated cardiac surgery. $N$ Engl J Med. 1989; 321:1437-1443.

28. Andersson TLG, Solem JO, Tengborn L, Vinge E. Effects of desmopressin acetate on platelet aggregation, von Willebrand factor, and blood loss after cardiac surgery with extracorporeal circulation. Circulation. 1990;81:872-878.

29. Seear MD, Wadsworth LD, Rogers PC, Sheps S, Ashmore PG The effect of desmopressin acetate (DDAVP) on postoperative blood loss after cardiac operations in children.J Thorac Cardiovasc Surg. 1989;98:217-219.

30. Lazenby WD, Russo I, Zadeh BJ, Zelano JA, Ko W, Lynch CC, Isom OW, Kneger KH. Treatment with desmopressin acetate in routine coronary artery bypass surgery to improve postoperative hemostasis. Circulation. 1990;82(suppl IV):IV-413-IV-419.

31. Hedderich GS, Petsikas DJ, Cooper BA, Leznoff M, Guerraty AJ, Poirier NL, Symes JF, Morin JE. Desmopressin acetate in uncomplicated coronary artery bypass surgery: a prospective randomized clinical trial. Can J Surg. 1990;33:33-36.

32. LoCicero J, Massad M, Matano J. Effect of desmopressin on hemorrhage without identifiable cause in coronary bypass patients. Ann Surg. 1991;57:165. Abstract.

33. Richardson DW, Robinson AG. Desmopressin. Ann Intern Med. 1985;103:228-239.

34. Czer L, Capon SM. Clinical experience in disorders of haemostasis. Drug Invest. 1990;2(suppl 5):32-44.

35. Chard RB, Kamm CA, Nunn GR, Johnson DC, Meldrum-Hanna $\mathrm{W}$. Use of desmopressin in the management of aspirin-related and 
intractible haemorrhage after cardiopulmonary bypass. Aust $N Z J$ Surg. 1990;60:125-128.

36. Rocha E, Llorens R, Páramo JA. Desmopressin and surgical hemostasis. N Engl J Med. 1990;322:1085. Letter.

37. Tice DA, Reed GE, Clauss RH, Worth MH. Hemorrhage due to fibrinolysis occurring with open heart operations. J Thorac Cardiovasc Surg. 1963;46:673-679.

38. Tice DA, Worth MH, Clauss RH, Reed GE. The inhibition of Trasylol of fibrinolytic activity associated with cardiovascular operations. Surg Gynecol Obstet. 1964;119:71-74.

39. Royston D, Bidstrup BP, Taylor KM, Sapsford RN. Effect of aprotinin on need for blood transfusion after repeat open-heart surgery. Lancet. 1987;2:1289-1291.

40. Bidstrup BP, Royston D, Sapsford RN, Taylor KM. Reduction in blood loss and blood use after cardiopulmonary bypass with high dose aprotinin (Trasylol). J Thorac Cardiovasc Surg. 1989;97: 364-372.

41. Havel M, Teufelsbauer H, Knöbl P, Dalmatiner R, Jaksh P, Zwölfer W, Müller M, Vukovich T. Effect of intraoperative aprotinin administration on postoperative bleeding in patients undergoing cardiopulmonary bypass operation. $J$ Thorac Cardiovasc Surg. 1991;101:968-972.

42. Mohr R, Goor DA, Lusky A, Lavee J. Aprotinin prevents cardiopulmonary bypass-induced platelet dysfunction: a scanning electron microscope study. Circulation. 1992;86(suppl II):II-405-II-409.

43. Czer LSC, Bateman TM, Cray RJ, Raymond M, Stewart ME, Lee S, Goldfinger D, Chaux A, Matloff JM. Treatment of severe platelet dysfunction and hemorrhage after cardiopulmonary bypass: reduction in blood product usage with desmopressin. J Am Coll Cardiol. 1987;9:1139-1147.

44. Mannucci PM, Lusher J. Desmopressin and thrombosis. Lancet. 1989;2:675-676.

45. Mannucci PM, Carlsson S, Harris AS. Desmopressin, surgery and thrombosis. Thromb Haemost. 1994;71:154-155.

46. Cosgrove DM, Heric B, Lytle BW, Taylor PC, Novoa R, Golding LAR, Stewart RW, McCarthy PM, Loop FD. Aprotinin therapy for reoperative myocardial revascularization: a placebo-controlled study. Ann Thorac Surg. 1992;54:1031-1038.

47. Gerbash PH, Lämmle B, Schüpbach P, Mühlemann W, Althaus U. Major coagulation disorders when using aprotinin: observations on a case. Thorac Cardiovasc Surg. 1991;39:196-198.
48. Kucuk O, Kwaan HC, Frederickson J, Wode L, Green D Increased fibrinolytic activity in patients undergoing cardiopulmonary bypass operation. Am J Hematol. 1986;23:223-229.

49. Holloway DS, Summaria L, Sandesara J, Vagher JP, Alexander JC, Caprini JA. Decreased platelet number and increased fibrinolysis contribute to postoperative bleeding in cardiopulmonary bypass patients. Thromb Haemost. 1988;29:62-67.

50. Páramo JA, Rifón J, Llorens R, Casares J, Paloma MJ, Rocha E. Intra- and postoperative fibrinolysis in patients undergoing cardiopulmonary bypass surgery. Haemostasis. 1991;21:58-64.

51. Teufelsbauer H, Proidl S, Havel M, Vukovich T. Early activation of hemostasis during cardiopulmonary bypass: evidence for thrombin mediated hyperfibrinolysis. Thromb Haemost. 1992;68:250-252.

52. MacGregor IR, Roberts EM, Prowse CB, Broomhead AF, Ozolins $M$. Fibrinolytic and hemostatic response to desamino-D-arginine vasopressin (DDAVP) administered by intravenous and subcutaneous routes in healthy individuals. Thromb Haemost. 1988;59: 34-39.

53. Van Oeveren W, Harder MP, Roozendaal KJ, Eigsman MD, Wildevuur CRH. Aprotinin protects platelets against the initial effect of cardiopulmonary bypass. J Thorac Cardiovasc Surg. 1990; 99:788-797.

54. Royston D. The serine antiprotease aprotinin (Trasylol ${ }^{\mathrm{TM}}$ ): a novel approach to reducing postoperative bleeding. Blood Coagul Fibrinolysis. 1990;1:55-69.

55. Orchard MA, Goodchild CS, Prentice CRM, Davies JA, Benoit SE, Creighton-Kemsford LJ, Gaffney PJ, Michelson HD. Aprotinin reduces cardiopulmonary bypass-induced blood loss and inhibits fibrinolysis without influencing platelets. $\mathrm{Br} \mathrm{J}$ Haematol. 1993;85:533-541.

56. Vander Salm TJ, Ansell JE, Okike ON, Marsicano TH, Lew R, Stephenson WP, Rooney K. The role of epsilon-aminocaproic acid in reducing bleeding after cardiac operation: a double blind randomized study. J Thorac Cardiovasc Surg. 1988;95:538-540.

57. Horrow JC, Hlavacek J, Strong MD, Collier W, Brodsky J, Goldman SM, Goel IP. Prophylactic tranexamic acid decreases bleeding after cardiac operations. J Thorac Cardiovasc Surg. 1990; 99:70-74.

58. Horrow JC, Van Riper DF, Strong MD, Brodsky I, Parmet JL. Hemostatic effects of tranexamic acid and desmopressin during cardiac surgery. Circulation. 1991;84:2063-2070. 